\title{
Antidepressants and Sexual Dysfunctions: a Translational Perspective
}

\author{
Jocelien D. A. Olivier ${ }^{1}$ • Berend Olivier ${ }^{1,2,3}$
}

Published online: 17 July 2019

(C) The Author(s) 2019

\begin{abstract}
Purpose of Review Antidepressants including selective serotonin re-uptake inhibitors (SSRIs) have sexual side effects contributing to treatment cessation. Animal models predicting such effects are needed to develop better antidepressants. Models of normal male rat sexual behavior and a genetic model simulating chronic SSRI-treatment, the serotonin transporter (SERT)knockout rat, have been developed. Our goal was to use both models to improve prediction of antidepressants without sexual side effects.

Recent Findings Male rats tested weekly for sexual behavior develop a stable sexual phenotype. Normal ejaculating males were used to test antidepressants, and results fit the typical human profile: SSRIs only exert inhibiting effects after chronic administration of antidepressants. Novel SSRI-antidepressants (vilazodone, vortioxetine) with additional serotonergic mechanisms lack inhibition of sexual behavior in line with human data. SERT-KO rats display lower basal sexual behavior than wildtypes at a level comparable with chronic SSRI-treated rats.

Summary The wild-type model generates results highly translatable to human sexual behavior. The SERT-KO model provides possibilities to study non-SSRI mechanisms in antidepressants.
\end{abstract}

Keywords Selective serotonin reuptake inhibitors - Animal model of male sexual behavior - Serotonin transporter knockout rat . Sexual side effects $\cdot$ Antidepressants $\cdot$ Translational research

\section{Introduction}

Many available antidepressants, including tricyclic antidepressants (TCA), monoamine oxidase inhibitors (MAOI), selective serotonin reuptake inhibitors (SSRI), and serotonin-noradrenalin reuptake inhibitors (SNRI) are associated with sexual dysfunctions in humans [1-4]. Serotonergic antidepressants may cause

This article is part of the Topical Collection on Preclinical and Psychophysiology

Berend Olivier

b.olivier@uu.nl

1 Behavioural Neuroscience Unit, Neurobiology Department, Groningen Institute for Evolutionary Life Sciences, University of Groningen, Nyenborgh 7, 9747, AG Groningen, the Netherlands

2 Department of Psychopharmacology, Utrecht Institute for Pharmaceutical Sciences, Utrecht University, Utrecht, the Netherlands

3 Department of Psychiatry, Yale University School of Medicine, New Haven, USA mild-to-severe sexual dysfunctions including decreased libido, delayed orgasm, and arousal difficulties. Major depressive disorder is associated with a 50-70\% enhanced risk of sexual dysfunction (SD), whereas SD itself increases the risk for depression also, up to a twofold greater risk [5••]. Prescribing antidepressants to depressed patients with potential sexual dysfunctions strongly enhances the risk for non-compliance or discontinued drug treatment [5••]. Although no conclusive evidence has been found, some antidepressants (agomelatine, bupropion, desvenlafaxine, moclobemide, trazodone, vilazodone, and vortioxetine) are considered to have less or no inhibitory sexual effects [4-6]. Prescription of a particular antidepressant is therefore dependent on a thorough assessment of sexual functioning of patients before and during therapy. Although complaints about sexual side effects of antidepressants are well-known [7-9], the cause and mechanisms involved have emerged more recently. Fundamental research into causative mechanisms of antidepressant-induced sexual dysfunction in humans is rather complex. Therefore, animal models with a high translational value are important for discovery of the underlying mechanisms and are needed to screen newly discovered chemicals targeted to be developed as novel antidepressants. 
For many years, our group has been interested in developing animal models of sexual behavior with a high translational value towards human sexual behavior and its dysfunctions [10-12].

\section{Development of a Male Rat Sexual Behavior Model That Is Translatable to Human Male Sexual (Dys) function}

To develop an animal model to screen antidepressants (but also other psychoactive drugs) in male sexual behavior, we extensively run sexual behavior tests in male rats. In a routine test, an adult male rat is placed for 30-min in a cage, followed by a 30-min sex test with an estrus female [13]. During this sex test, male sexual behavior (number of ejaculations (E)/30 min; and during the first ejaculation series: the number of mounts (MF), intromissions (IF), latencies to start mounting (ML) and intromission (IL), latency to the first ejaculation (EL) and post-ejaculation interval (PEI)) are recorded. Initially, sexual behavior of male rats is rather unstable; at least 4 (sometimes 6) training tests (once a week) are needed to stabilize sexual behavior $[10,14,15]$. Once at this level, male sexual behavior is stable over time (at least up to 12 months). In this way, we collected sexual behavior of many rats and found extensive variation in individual sexual performance. In a 30 -min test, male rats ejaculate from 0 to 5 times, based on data of more than 2000 rats over the last decades [10, 16, 17]. Ejaculation latencies show a reverse pattern; the fewer the number of ejaculations, the longer the ejaculation latencies. These data resemble data on human male ejaculation. Research on human ejaculations was furthered in the 1990s by findings that SSRIs lengthened the intravaginal ejaculation latency times (IELTs) of males with lifelong premature ejaculation (LLPE). Waldinger and Olivier [12] postulated that LLPE men with IELTs smaller than $1 \mathrm{~min}$ are part of normal biological variation in the EL, with a putative genetic component [18-20]. According to this variation, there are men with lifelong early ejaculation, men with lifelong delayed or even no (an) ejaculation, and men ejaculating in a range characterized as having "normal" ejaculation time. When the number of trained male rats was plotted against the ejaculation frequencies of individual rats (from 0 to $5 \mathrm{E} /$ test), a Gaussian distribution curve emerged, where approx. 10$20 \%$ of the rats displays "hyposexual" $(0-1$ E/test $)$ and approx. 10\% "hypersexual" behavior (4-5 E/test). Remaining animals ("normal-sexual") display 2-4 E/test. We hypothesize that these different phenotypes might model different aspects of the human ejaculation spectrum: "sluggish" rats $(0-1 \mathrm{E} / \mathrm{test})$ might model delayed or an-ejaculation, whereas "rapid" or "fast" rats (4-5 E/test) might model premature ejaculation. We use "normal" ejaculating rats for most pharmacological studies, particularly antidepressants, because their level of sexual activity enables detecting both stimulating and inhibitory effects of drugs. In our early studies [21, 22], male rats with various levels of sexual experience were used to study $5-\mathrm{HT}_{1 \mathrm{~A}}$-receptor agonists and $\alpha_{2}$ adrenoceptor antagonists. 5- $\mathrm{HT}_{1 \mathrm{~A}}$-receptor agonists $(8-\mathrm{OH}-$ DPAT, flesinoxan, buspirone, and ipsapirone) and $\alpha_{2}-$ adrenoceptor antagonists (yohimbine, idazoxan) facilitated sexual behavior of sexually naïve rats (low number of ejaculations), whereas in moderately experienced males (intermediate number of ejaculations), only 8-OH-DPAT and

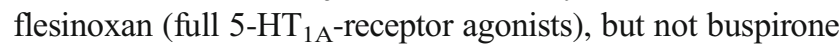
and ipsapirone (partial 5- $\mathrm{HT}_{1 \mathrm{~A}}$-receptor agonists), facilitated sexual behavior. In sexually vigorous males (high number of ejaculations), none of the 5- $\mathrm{HT}_{1 \mathrm{~A}}$-receptor agonists or $\alpha_{2}$ adrenoceptor antagonists influenced male sexual behavior, probably due to a ceiling effect. This kind of data, in combination of studies of inhibitory drugs on male sexual behavior [23], established the value of this animal model of male sexual behavior in determining the potential of drugs to influence human sexual behavior.

\section{Olfactory Bulbectomy and Depression}

An important issue in the last decades has been the impact of antidepressants on sexual functioning. Antidepressants, particularly serotonergic antidepressants like SSRIs, SNRIs, and tricyclics (especially clomipramine) are notorious for their sexual side effects $[4,7,9,24,25]$. The onset of antidepressant action starts gradually (weeks), and sexual side effects parallel the antidepressant action. An animal model with predictive validity for this human profile should reflect this relatively slow onset of action. One of the big items in the research and discovery of new and innovative antidepressants is the availability of animal models that are able to measure "onset of action," "efficacy," and "side effects" [26]. Onset of antidepressant action in an animal model is quite difficult to assess. Most animal depression tests are acute, in that they respond immediately to a dose of a certain antidepressant, e.g., forced swim test or tail-suspension test. Animal depression models that do not respond acutely but only after chronic treatment of the classic antidepressants are rather scarce, although indispensable in the onset of action discovery. One of such models is the olfactory bulbectomized (OBX) rat [26, 27]. OBX leads to stable and lasting changes in behavior after removing the olfactory bulbs [27]. OBX leads within days after ablation to permanent changes in activity, basal body temperature, heart rate, and heart rate variability and stress responsitivity [28]. Increased locomotor activity in an open field is an often-used simple parameter to measure the effects of antidepressants [27, 29]. In an extensive review on available animal models, olfactory bulbectomy in rodents is considered superior to other animal models to detect onset of action of antidepressants [26], with a high sensitivity, 
specificity, and reliability and moderate ease to use the model. In rats, we use the olfactory bulbectomized (OBX) model to detect the onset of antidepressant action of drugs [30]; SSRIs (e.g., paroxetine, escitalopram) only inhibit OBX-induced hyperactivity after chronic, but not acute treatment [29]. In the male rat sexual behavior model, a similar profile emerges; no inhibition of sexual behavior after acute, but after chronic (714 days) administration of SSRIs (paroxetine, citalopram, fluoxetine) $[16,17,31-33]$.

\section{Pharmacological Effects in Male Sexual Behavior Model}

Table 1 summarizes the acute and chronic effects of antidepressants and potential antidepressants on sexual behavior in our rat model and also indicates effects in humans (based mainly on effects in either depressed patients or premature ejaculating males). Because depression itself is associated with sexual dysfunctions, the effects of medications are difficult to establish. Extra support for specific influences of drugs on sexual functions, at least in males, can be found in drug studies in premature ejaculation [63••]. Males with LLPE do not suffer from depression or anxiety disorders. Therefore, the LLPEparadigm seems an "ideal" model to study effects of drugs on ejaculation. In general, pharmacological treatment for premature ejaculation (PE) aims at delaying the ejaculation latency time (operationally defined as the intravaginal ejaculation latency time-IELT). SSRIs lengthen IELT but significant effects only occur after chronic treatment (weeks). The disadvantage of taking (off-label prescribed) chronic SSRIs to obtain acceptable ejaculation latencies has led to attempts to develop "on-demand" treatment for PE, medication that one can use only when it is required for a better sexual performance. Although clomipramine, a tricyclic antidepressant with strong serotonergic, but also noradrenergic reuptake blockade and $\alpha_{1}$-adrenolytic, anticholinergic, and anti-histaminergic properties, has some ondemand effects in PE [34], but accompanying adverse side effects probably restrict its use, including dry mouth, blurred vision, constipation, dizziness, and nausea. More recently, dapoxetine was developed for PE, a relatively short-acting SSRI, and approved for on-demand treatment of LLPE in adult men in Europe. The effects of dapoxetine in PE are relatively minor and, like all SSRIs, come with side effects [64•]. Dapoxetine is, like other SSRIs, selective for the serotonin transporter (SERT) but is somewhat less potent than fluoxetine and paroxetine. Investigators explain dapoxetine's rapid onset of action by its pharmacokinetic profile pointing at its rapid absorption and elimination compared with classic SSRIs [65-67]. This would imply that dapoxetine would not lead to $5-\mathrm{HT}_{1 \mathrm{~A}}$-autoreceptor activation like the other SSRIs [68]. Although dapoxetine is registered as on-demand therapeutic in some countries, it is not very effective [cf. 69]. In our rat model, SSRIs do not acutely inhibit ejaculation $[14,16,70]$. An extremely high dose of dapoxetine $(300 \mathrm{mg} / \mathrm{kg}$ orally, $3 \mathrm{~h}$ before testing) reduced sexual behavior in "rapid" ejaculating rats, although dapoxetine has not been tested in slow "ejaculators" [68]. In our sex model, dapoxetine $(11 \mathrm{mg} / \mathrm{kg}$, PO) was tested at a dose molecularly equivalent to paroxetine $(10 \mathrm{mg} / \mathrm{kg}, \mathrm{PO})$ and we found no acute inhibitory effects from either drug on
Table 1 Summary of effects of various drugs on male sexual behavior after acute, sub-chronic, or chronic treatment. $\downarrow$, inhibition; $\uparrow$, stimulation; 0 , no effect; nt, not tested. SSRI, selective serotonergic reuptake inhibitor;
SNRI, serotonergic and noradrenergic reuptake inhibitor; NDRI, noradrenergic and dopaminergic reuptake inhibitor; $T C A$, tricyclic antidepressant; $T R I$, triple monoaminergic reuptake inhibitor; $R$, receptor

\begin{tabular}{|c|c|c|c|c|c|}
\hline DRUG & Mechanism of action & Rat acute & Rat chronic & Human sexual behavior & References \\
\hline Paroxetine & SSRI & 0 & $\downarrow$ & $\downarrow$ & $\begin{array}{l}{[1-4,13,16,29,33-39,} \\
\quad 40 \bullet \bullet, 41-43]\end{array}$ \\
\hline Clomipramine & TCA & 0 & $\downarrow$ & $\downarrow$ & {$[7-11,13,16,23,34]$} \\
\hline Citalopram/escitalopram & SSRI & 0 & $\downarrow$ & $\downarrow$ & {$[13,16,38,39,44-46]$} \\
\hline Fluoxetine & SSRI & 0 & $\downarrow$ & $\downarrow$ & {$[13,31,32]$} \\
\hline Fluvoxamine & SSRI & 0 & $0 \downarrow$ & $0 \downarrow$ & {$[13,42]$} \\
\hline Sertraline & SSRI & 0 & $\downarrow$ & $\downarrow$ & {$[25,47,48]$} \\
\hline Venlafaxine & SNRI & 0 & $\downarrow$ & $\downarrow$ & {$[16,49]$} \\
\hline Buspirone & 5- $\mathrm{HT}_{1 \mathrm{~A}} \mathrm{R}$ agonist & $\uparrow$ & 0 & 0 & {$[16,50]$} \\
\hline Bupropion & NDRI & $\uparrow$ & 0 & $\uparrow$ & {$[16,36,37,44,47-49]$} \\
\hline DOV216,303 & TRI & 0 & $\downarrow$ & $\mathrm{nt}$ & {$[30,51-53]$} \\
\hline Vilazodone & $\mathrm{SSRI}+5-\mathrm{HT}_{1 \mathrm{~A}} \mathrm{R}$ agonist & 0 & 0 & $0 ?$ & {$[39,40 \bullet \bullet, 45,54-56]$} \\
\hline Hypidone & $\mathrm{SSRI}+5-\mathrm{HT}_{1 \mathrm{~A}} \mathrm{R}$ agonist & 0 & 0 & $\mathrm{nt}$ & {$[33]$} \\
\hline Vortioxetine & $\begin{array}{l}\mathrm{SSRI}+5-\mathrm{HT}_{1 \mathrm{~A} / 1} \mathrm{~B} \text { agonist and } 5-\mathrm{HT}_{1} \mathrm{D}, 5-\mathrm{HT}_{3} \\
\text { and } 5-\mathrm{HT}_{7} \text { antagonist }\end{array}$ & 0 & 0 & 0 & {$[54,57,58,59 \cdot \bullet]$} \\
\hline Tramadol & SNRI $+\mu$-opioid agonist & $0 \downarrow$ & NT & $\downarrow$ & {$[41,60,61 \cdot, 62]$} \\
\hline
\end{tabular}


male sexual behavior in "normal" ejaculating rats (approx. 2 E/test).

All SSRIs share the inhibitory action on male sexual behavior after chronic, but not acute administration (see Table 1). This pattern clearly follows the antidepressant profile, which also emerges only after some delay. Apparently, mechanisms underlying inhibitory effects of chronic SSRIs reflect changes in the serotonergic system only becoming manifest after sustained administration. The underlying hypothesis, increased serotonin-mediated tonic inhibition, suggests that chronic SSRI treatment influences underlying circuitry mediating sexual behavior by enhancing 5-HT activity in projection areas [71]. Although it is not at all clear how this mechanism specifically acts at various brain levels, it is evident that a very complex network in the brain and spinal cord is involved in this serotonergic-induced action, including important roles for noradrenergic, dopaminergic, and glutamatergic systems $[72,73]$.

\section{Noradrenaline and Dopamine}

The serotonin-noradrenaline reuptake inhibitor (SNRI) venlafaxine affects male sexual behavior at relatively high doses [16] (Table 1). Because noradrenaline facilitates sexual behavior in humans [16], one might expect that this may antagonize inhibitory effects of the SSRI-component in venlafaxine. Only lower doses venlafaxine do not affect sexual behavior, indicating that SSRI activity at higher doses becomes dominant in venlafaxine's action. The dopaminergic (DA) system plays an important role in the facilitation of sexual behavior and DA activity in mesolimbic areas is involved in motivational and copulatory aspects [72]. There is a strong 5-HT/DA interaction in the brain that modulates motivational aspects of sexual performance [16] and adding a dopaminergic stimulating mechanism to an inhibiting serotonergic mechanism (e.g., SSRI) might result in amelioration of the inhibitory action of the latter [16]. DOV 216,303 is a triple reuptake inhibitor (TRI) blocking noradrenergic, serotonergic, and dopaminergic transporters [51, 52]. One of the core symptoms of depression, anhedonia, is connected to lower mesolimbic DA neurotransmission and the original rationale for development of TRIs was to alleviate anhedonia in depression [52]. An additional advantage might be that the dopaminergic stimulation by DA-reuptake inhibition might reverse sexual side effects. No data are available on the sexual side effect profile of TRIs, but a trial with a TRI (the DOV 216,303 isomer amitifadine) showed no worsening of sexual functioning after chronic treatment of depressed patients [53]. Our preclinical data confirm lack of sexual side effects of DOV 216,303 at antidepressant doses in animal depression models $[30,35,52,74]$. This clearly suggests that 5 -HT-mediated inhibition of sexual behavior can be overcome by stimulating dopaminergic neurotransmission via DAT-blockade, although a noradrenergic role cannot be excluded.

Bupropion is used to counteract SSRI-induced sexual dysfunction [36, 37, 44, 47-49]. Bupropion facilitates noradrenergic and dopaminergic mechanisms (NET and DAT inhibitor), and we expected a rather strong pro-sexual effect of bupropion in our animal model. Bupropion had a slight stimulating effect, but only at a higher dose and only after acute and (marginally) after sub-chronic but not chronic administration. This small and short-living facilitating effect was unexpected, but likely explains why bupropion is not used in PE. Apparently, its relatively weak DAT blockade is not strong enough to permanently stimulate sexual behavior in healthy subjects (like our rats), leaving open the possibility that in "depressed" brains with an extra SSRI-induced sexual dysfunction, bupropion might be very effective as an "add-on" medication.

When an SSRI is given (either to man or animal), the pharmacological mechanism, blockade of the SERT on the neuron, induces an increase in the level of 5-HT in the synaptic cleft [75]. 5-HT is the endogenous ligand of all 14 different 5-HT receptors and it is very likely that some, but not all 5-HT receptors are involved in serotonin's action in sexual behavior [76••]. A critical receptor involved is the $5-\mathrm{HT}_{1 \mathrm{~A}} \mathrm{R}$, located as somatodendritic autoreceptor on 5-HT cell bodies and postsynaptic heteroreceptor on many non-serotonergic neurons in various brain areas [75]. 5- $\mathrm{HT}_{1 \mathrm{~A}}$-receptor agonists, including buspirone, have acute pro-sexual activity in rats [77, 78]. This pro-sexual activity of $5-\mathrm{HT}_{1 \mathrm{~A}}$-receptor agonists is most likely due to activation of postsynaptic 5- $\mathrm{HT}_{1 \mathrm{~A}}$-receptors, probably mediating dopaminergic activation in brain areas that decrease the ejaculation threshold [78]. Clinically, the only available (partial) 5- $\mathrm{HT}_{1 \mathrm{~A}}$-receptor agonist buspirone (also dopamine $\mathrm{D}_{2}$-receptor antagonist) is used as an antidepressant and has not been associated with sexual side effects $[38,50]$. In our rat model, low doses of buspirone that exert an antidepressant effects in animal depression models [79] have mild prosexual activity [16] (Table 1). Our rat data are in line with (limited) human data indicating that buspirone has no sexual side effects, but is also not a strong (add-on) drug in combination with SSRIs. The absence of pro-sexual effects at the highest dose probably reveals the dopamine $\mathrm{D}_{2}$-receptor antagonistic effect of buspirone. Dopamine $\mathrm{D}_{2}$-receptor blockade strongly inhibits sexual behavior and at higher doses interferes with pro-sexual activity of $5-\mathrm{HT}_{1 \mathrm{~A}}$-receptor stimulation.

\section{New Antidepressants}

Non-SSRI antidepressants like agomelatine and mirtazepine lack sexual side effects $[80,81]$. Augmentation therapy with mirtazapine seems to decrease the sexual side effects of SSRIs $[82,83]$, supporting that SSRI-induced sexual dysfunction 
may be mediated by $5-\mathrm{HT}_{2 \mathrm{C}}$-receptors. The selective $5-\mathrm{HT}_{2 \mathrm{C}^{-}}$ receptor antagonist S32006 has antidepressant effects in preclinical depression models and elevates extracellular DA and NA, but not 5-HT [84, 85]. S32006 had no effects on sexual behavior [16], suggesting that $5-\mathrm{HT}_{2 \mathrm{C}}$-receptors are not (directly) involved in SSRI-induced sexual side effects.

Recently, novel antidepressants were introduced, vilazodone and vortioxetine. Vilazodone is an SSRI and partial 5 - $\mathrm{HT}_{1 \mathrm{~A}}$-receptor agonist with antidepressant activity in man and rat. Clinical trials indicate absence of sexual side effects in depressed patients $[45,54,55]$. Vilazodone and the SSRIs citalopram and paroxetine were tested in our rat model [39]. Vilazodone did not affect sexual behavior neither after acute nor chronic administration, whereas both citalopram and paroxetine showed the typical SSRI profile. In a subsequent experiment once daily, paroxetine, vilazodone, paroxetine plus buspirone (simulating the mechanism of action of vilazodone), or vehicle were given for 14 days to male rats and then switched for 7 days to various treatments [40••]. Vehicle, paroxetine, and vilazodone pretreated groups were switched to vehicle; paroxetine pretreated groups were switched to vilazodone, paroxetine plus buspirone, or vehicle, whereas the paroxetine plus buspirone group was switched to paroxetine alone. Sexual behavior was scored acutely, after subchronic and chronic dosing, as well as 7 days after switching. Combination of paroxetine plus buspirone, like vilazodone alone, did not affect sexual behavior, while paroxetine alone reduced it considerably. Switching to paroxetine in both the paroxetine plus buspirone group as well as in the vilazodone group clearly inhibited sexual behavior. These data strongly suggest that $5-\mathrm{HT}_{1 \mathrm{~A}}$-receptor stimulation by vilazodone counteracts the inhibitory action of the SSRI mechanism. These preclinical data strongly support clinical absence of sexual side effects. Moreover, adding a 5- $\mathrm{HT}_{1 \mathrm{~A}^{-}}$ receptor agonist to an SSRI may counteract SSRI-induced sexual dysfunctions. Hypidone, in preclinical development, has a comparable mechanistic profile like vilazodone and has no sexual inhibitory action either after acute or chronic administration in a comparable sexual behavior model [33]. Another recently developed antidepressant, vortioxetine, is an SSRI with a complex serotonergic profile. Next to inhibiting SERT, it is a $5-\mathrm{HT}_{1 \mathrm{~A} / 1 \mathrm{~B}}$-receptor agonist and $5-\mathrm{HT}_{3,7,1 \mathrm{D}}$-receptor antagonist $[57,58]$. Vortioxetine did not affect sexual behavior in male rats, neither after acute nor chronic dosing [59••]. The doses used led up to $90 \%$ (at $10 \mathrm{mg} / \mathrm{kg}$ ) SERT occupation, comparable with paroxetine (at $10 \mathrm{mg} / \mathrm{kg}$ ) with 90\% SERT occupancy, indicative that at least at the highest dose tested, vortioxetine exerted sufficient SERT occupancy to potentially induce sexual side effects comparable with paroxetine. The remaining serotonergic mechanisms in vortioxetine therefore in some way counteract SSRI-induced inhibitory effects. Based on our findings, vortioxetine may be devoid of sexual side effects in depressed patients. Clinical findings, although not explicitly aimed to study the sexual side effects of vortioxetine, confirm this profile $[56,58]$.

\section{Miscellaneous Treatment Options for Premature Ejaculation}

Various on-demand treatments are in use in males with premature ejaculation, including tramadol, phosphodiesterase type-5 (PDE-5) inhibitors, topical anesthetic Fortacin ${ }^{\mathrm{TM}}$ (lidocaine + prilocaine (spray)), and various over-the-counter topical anesthetics (not officially registered) [33]. Tramadol is, based on its $\mu$-opioid agonistic mechanism, mainly used for pain treatment, but has also serotonergic and noradrenergic reuptake inhibiting properties. Although not used as antidepressant and not registered, tramadol is effective in PE [60, 63] and has been (off-label) used as on-demand treatment for LLPE [41], although its potential risk for opioid addiction remains a serious obstacle [64]. Tramadol has acute sexual inhibiting effects in our rat model [61•], supporting its potential on-demand character in PE. Pharmacological experiments suggest that tramadol's inhibitory action is mainly due to the SSRI mechanism although a small $\mu$-opioid receptor agonistic effect might be involved [61•]. Fortacin is officially approved for LLPE by the EMA (European Medicine Association), but not by the FDA. It is an aerosol spray that delivers topical anesthesia to the glans penis and can be used for on-demand treatment. PDE-5 inhibitors are registered for the treatment of erectile dysfunction, and their use for treatment of PE is controversial. The (not-registered) use of topical anesthetics (creams and sprays) is effective in delaying ejaculation in men with lifelong and acquired PE comparable with Fortacin.

Conclusion Our male rat model of sexual behavior has strong translational value for predicting sexual (side) effects of psychoactive drugs in human males, including depressed and healthy persons. The predictive validity of the model is illustrated by the comparability of the effects of SSRI antidepressants in depression and premature ejaculation and effects in the rat model. The rat model is able to predict the sexual behavior (side effect) profile of new antidepressants in humans and its onset of action.

\section{A Genetic Model of SSRI-Induced Sexual Dysfunction}

Chronic SSRI treatment is needed to effectuate antidepressant and sexual inhibiting effects in rodents and men. These delayed effects are initially triggered by blocking the SERT but are due to neuroplasticity changes induced by chronic exposure, viz. by selective desensitization of somatodendritic 5$\mathrm{HT}_{1 \mathrm{~A}}$-autoreceptors and associated downregulation of SERT-activity by internalizing processes [86, 87•]. Because of the widespread distribution of serotonergic synapses in the brain and its modulating role in various processes, it is not surprising that many systems are affected when serotonin 
levels are chronically elevated $[88 \bullet \cdot]$. The production of the SERT-knockout rat by ENU-mutagenesis [89] provided us with a genetic model of chronic-enhanced brain 5-HT, highly comparable with chronic SSRI-treatment [90]. Biochemical characterization of SERT-knockout rats revealed a gene dose-dependent reduction in the SERT-expression and function: SERT mRNA and functional SERT protein are $100 \%$, resp. 50\% absent in full (-/-) and partial SERT-knockouts $(+/-)$. 5-HT homeostasis is severely affected in the SERT-/rats characterized by high extracellular 5-HT levels and reduced 5-HT intracellular levels and release. No major adaptations were found in non-serotonergic systems, including dopamine and noradrenaline tissue levels, dopamine metabolites, DAT and NET densities, and in vitro depolarizationinduced release of dopamine, noradrenaline, acetylcholine, GABA, and glutamate [90]. SERT-/- rats, like SERT-/mice, show disturbed serotonergic systems and various behavioral (e.g., exploration, aggression, nociception, anxiety, fear)
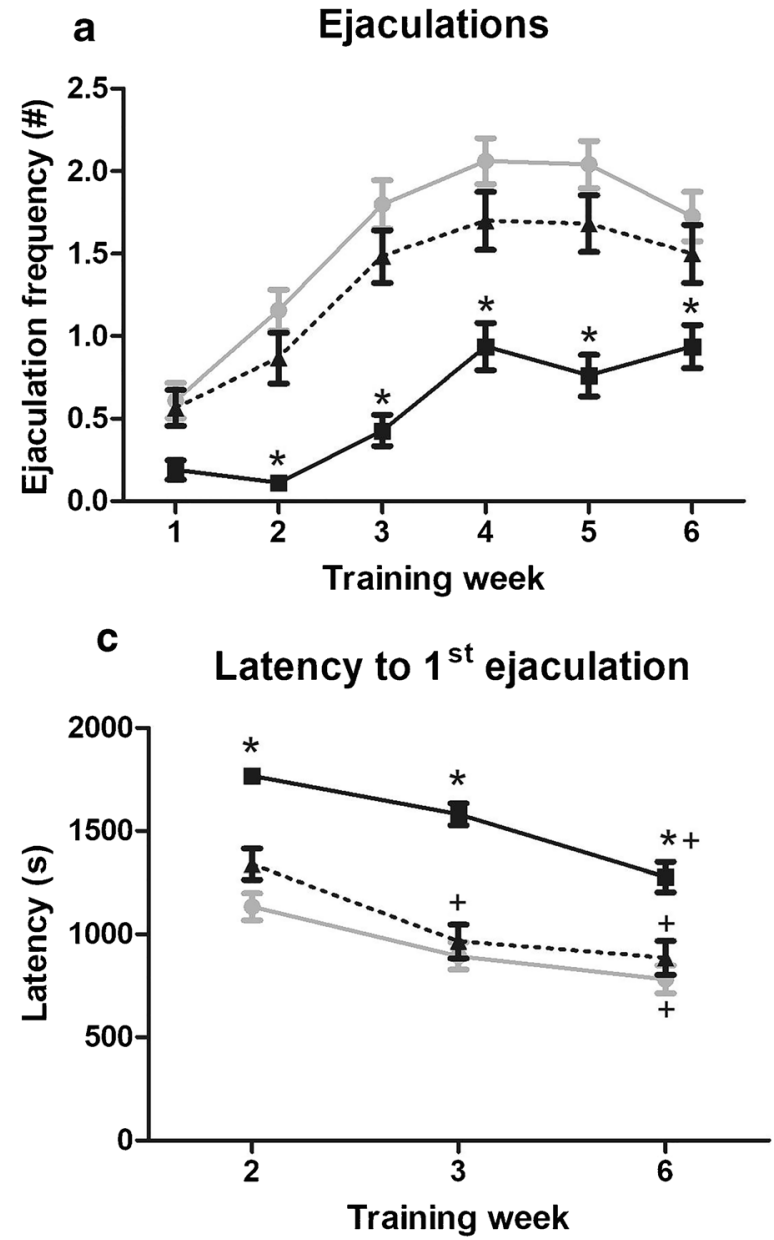

Fig. 1 a The mean number of ejaculations $(+/-$ SEM) for the three genotype groups (SERT $+/+(N=95)$; SERT $+/-(N=60)$, and SERT $-/-$ $(N=63)$ of male rats is shown for the successive 6 weekly training test of 30 min with an estrus female. $*=$ significant difference from the SERT+/+ and SERT+/- groups. b The distribution of the number of animals with particular phenotypes ( 0 to 5 ejaculations/test) in the last and physiological changes (e.g., temperature regulation, sleep), largely due to (disturbed) developmental processes [91]. Interestingly, male SERT-/- rats have a lower basal level of sexual behavior than SERT+/+ rats [62, 92].

We studied the development of sexual (endo)phenotypes over the first six weekly 30 -min training tests in male SERT+/+, SERT+/-, and SERT-/- rats. The number of ejaculations is portrayed in Fig. 1a. All genotypes improve their sexual behavior over time; after approx. three tests, a stable sexual phenotype emerges (Fig. 1a). From the second test on, SERT $+/+$ and SERT $+/-$ ejaculate more than SERT $-/-$ rats, confirming earlier findings $[62,92]$. Figure $1 \mathrm{~b}$ shows the distribution of animals with zero to five ejaculations during the last (sixth) training test. In line with overall lower ejaculation numbers in the SERT $-/-$ group, its frequency distribution has shifted. In particular, animals never ejaculating in any test (indicated by $0 *$ ), form a rather large group within the SERT -/- group; no SERT $-/-$ animal ejaculated more than three

\section{b $\quad$ Training week 6}
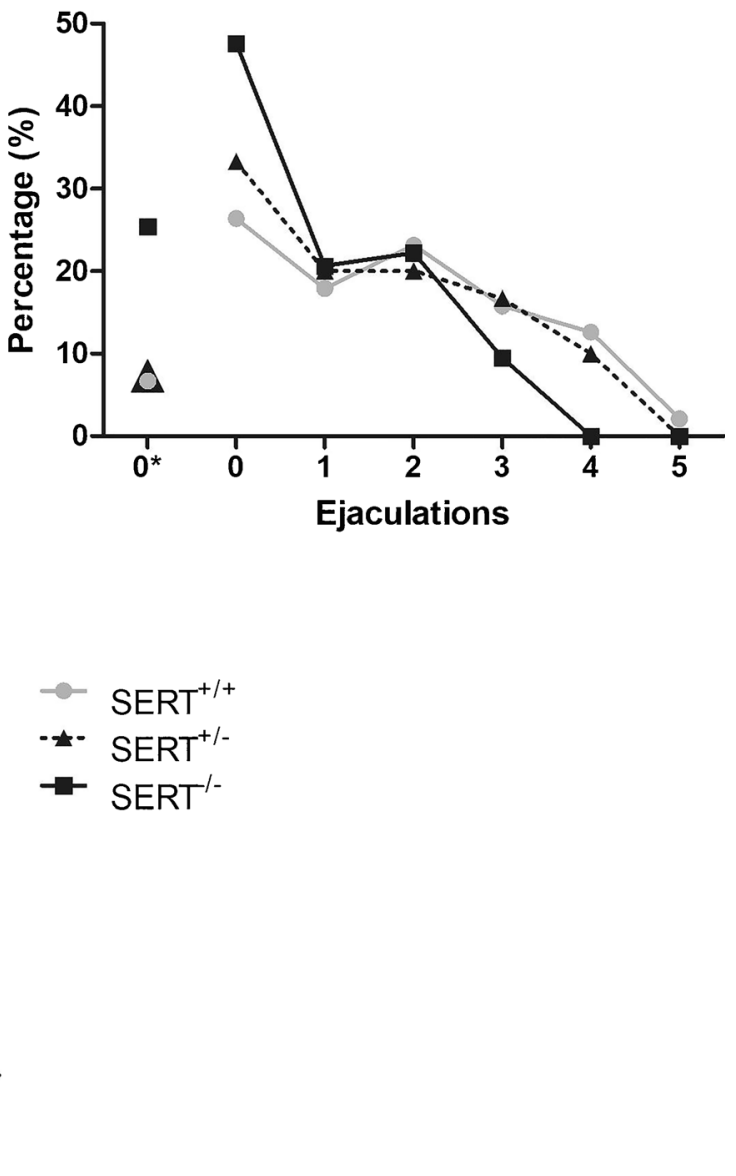

(6th) training test. $0^{*}=$ depicts the animals that never ejaculated during all the training tests (they are also included in the 0 ejaculations group). $\mathbf{c}$ The latencies to the first ejaculation for the three genotype groups are shown during training weeks 2,3 , and 6 . * $p<0.05$ compared with the SERT+/and WT groups; $+p<0.05$ compared with week 2 
times during a test. Figure 1c shows the latency of the first ejaculation (EL1) for the three genotypes at weeks two, three, and six. Along with the increase in ejaculations over time, decreases occur in the EL. SERT+/+ and SERT+/- never differed, but ELs were always longer in the SERT $-/-$ rats.

Comparable profiles occur after chronic SSRI-treatment $[10,16]$, indicating that enhanced brain 5 -HT levels inhibit male sexual behavior. It is hypothesized that, dependent on the intrinsic basal sexual phenotype (whether males, after training, stably display from 0 to $5 \mathrm{E} / \mathrm{test}$ ), enhanced 5-HT activity leads to genotype-dependent decreases in individual sexual performance. Dependent on the intrinsic basal sexual phenotype (whether males, after training of at least 3 weeks, stably display from 0 to $5 \mathrm{E} /$ test), enhanced 5-HT activity in some way leads to genotype-dependent decreases in individual sexual performance. Although we have not yet extensively looked into our historic data (over the last decades more than 2500 male rats were tested on their basal, trained sexual level), it might lead, if true, to further support for our hypothesis that high-performing male rats may model $\mathrm{PE}$ in men, whereas low-performing rats may model delayed or an-ejaculation. Human studies about the functioning of the serotonergic system in various ejaculation or other sexual disturbances are not available, let alone in the distribution of ejaculation latencies in the normal male population.

Typically, SERT+/- rats that have around $50 \%$ active SERTs, never behaviorally differed from SERT+/+ in male sexual behavior. Apparently, if a minimal number of SERTs is present in the brain, the serotonergic system (at least with regard to sexual behavior) is fully capable of normal modulation of this behavior. In most studies in SERT $+/-$ genotypes in rats and mice, this genotype does not show robust phenotypes [91]. The SERT+/- genotype has, from a molecular and biochemical perspective, some resemblance to 5-HTTLPR polymorphisms in humans, but a relationship between this polymorphism and male sexual behavior is not clear.

We used male SERT-/- rats in pharmacological experiments. Obviously, SSRIs have no effect, but the model is able to investigate other brain mechanisms involved in antidepressant activity. The model can also be used to test drugs that have multiple mechanisms of actions in addition to SSRI properties, such as vortioxetine and vilazodone.

Tramadol is such an example, as it has been used as ondemand treatment of PE [64•]. Tramadol is a racemic mixture, with two pharmacologically active enantiomers [93]. The (+)enantiomer and its metabolite ((+)-M1) are $\mu$-opioid receptor agonists and have SSRI properties; the (-)-enantiomer and its metabolite ((-)-M1) have NRI properties [94]. In normal rats, tramadol acutely inhibited male sexual behavior, mainly due to its SSRI-properties, although some $\mu$-opioid receptor stimulation was involved [61]. Tramadol in SERT-/- rats still inhibited sexual behavior, but extensive pharmacological studies involving $5-\mathrm{HT}_{1 \mathrm{~A}}$-receptor and $\mu$-opioid receptor antagonism and combined blocking of both receptors did not yet completely unravel the probable underlying sexual inhibiting mechanism of tramadol, apart from its SSRI mechanism [62].

Although the SERT is lacking from conception on in the SERT $-/-$ rat, it is not clear what effects this has on other neurotransmitter systems in the brain. During development, several adaptive mechanisms may play a role and may compensate for the lost SERT, e.g., some evidence emerged that DAT and/or NET may have taken over some of the serotonin transport [61•]. Moreover, it is known that $5-\mathrm{HT}_{1 \mathrm{~A}}$-autoreceptors are desensitized in SERT-1rodents [92]. 8-OH-DPAT, a potent $5-\mathrm{HT}_{1 \mathrm{~A}}$-receptor agonist, has pro-sexual activity in male SERT $+/+$, SERT $+/-$, and SERT $-/-$ rats [92]. Although basal level of sexual behavior is lower in SERT $-/-$ rats, dose-response curves for pro-sexual activity of 8OH-DPAT were comparable, indicating that the group (pool) of 5$\mathrm{HT}_{1 \mathrm{~A}}$-receptors involved in this mechanism is intact in the SERT $-/-$ rats. The selective $5-\mathrm{HT}_{1 \mathrm{~A}}$-receptor antagonist WAY100.635 has no effects in male sexual behavior of SERT $+/+$ and SERT +/genotypes. However, in SERT-/- rats, WAY100,635 dosedependently reduced sexual behavior [92]. Combination of prosexual doses of 8-OH-DPAT with one dose of inactive WAY100635 (inactive in SERT+/+, but strongly reducing sexual behavior in SERT- -- rats) completely antagonizes pro-sexual effects of 8-OH-DPAT in SERT+/+, but only partially in the SERT $-/-$ rats [92]. Based on these data, we hypothesize at least two populations of $5-\mathrm{HT}_{1 \mathrm{~A}}$-receptors involved in male rat sexual behavior. Normal sexual performance needs activation of a certain pool of $5-\mathrm{HT}_{1 \mathrm{~A}}$-receptors that are (permanently) desensitized in SERT-/-rats. A different pool of 5-HT ${ }_{1 \mathrm{~A}}$-receptors mediates prosexual effects of 8-OH-DPAT; they are not desensitized in SERT $-/-$ rats. It is likely that $5-\mathrm{HT}_{1 \mathrm{~A}}$-autoreceptors are involved in the basal level of sexual behavior of an individual rat. Permanent desensitization of this receptor, as found in the SERT $-/-$ and chronic SSRI-treated rats, leads to a low level of sexual behavior. That activation of $5-\mathrm{HT}_{1 \mathrm{~A}}$-receptors (other than autoreceptors) exerts comparable pro-sexual effects in the SERT $+/+$ and SERT+/- genotypes and, also in chronic SSRI-treated rats, strongly suggests that some pool of postsynaptic $5-\mathrm{HT}_{1 \mathrm{~A}^{-}}$ heteroreceptors is still functionally active. This is supported by findings that 8-OH-DPAT was able to antagonize chronic SSRIinduced inhibition of male rat sexual behavior $[42,43]$ and further inhibition by the $5-\mathrm{HT}_{1 \mathrm{~A}}$-receptor antagonist WAY100,635 adding to inhibition of chronic SSRI-treatment [46]. Further research where these $5-\mathrm{HT}_{1 \mathrm{~A}}$-heteroreceptors are located and how they modulate or contribute to the actual sexual behavior is needed and ongoing in our laboratory.

Conclusion Male SERT-/- rats constitute a genetic model simulating chronically SSRI-treated rats. Basal level of male sexual behavior is lower than the corresponding SERT+/+ genotype and resembles the level of chronically treated SSRIs like paroxetine at $90 \%$ SERT occupation. The resulting 
genotype can be used for acute pharmacological experiments to study, e.g., additional serotonergic mechanisms present in antidepressants, like vilazodone or vortioxetine that basically are SSRIs with additional mechanisms that in some way or another counteract sexual inhibiting effects of SERT-antagonism. Moreover, SERT-/- models can be used to study effects of lifelong elevated 5-HT on neuroplasticity processes that have led to the (mal)adapted brains of the SERT-/- genotype or that after chronically treated SSRIs.

\section{Overall Conclusions}

The most frequently used and first-line antidepressants, SSRIs and SNRIs, induce sexual side effects in depressed patients that increase the burden of the disease and often lead to cessation of treatment. Apart from other attributes like better efficiency and faster onset-of-action, new antidepressants have to be devoid of this serious side effect and animal models that may predict such effects are extremely useful. In this contribution, a male rat model of sexual behavior is presented. Basically, adult male rats are trained weekly on sexual behavior against an estrus female until they reach a stable sexual behavior (after three tests). Males that ejaculate on average two-three times during a test are used to study the effects of antidepressants after acute and chronic treatment. Antidepressants inhibit sexual behavior after chronic, but not acute administration, resembling the profile of antidepressants in humans. Interestingly, SSRIs and SNRIs are also used for treatment of premature ejaculation and are also only effective after chronic treatment. Our rat model is able to detect drugs that acutely (on-demand) inhibits (tramadol) or facilitates $\left(5-\mathrm{HT}_{1 \mathrm{~A}}\right.$-receptor agonists) sexual behavior. The model is therefore fit to detect inhibitory sexual (side effects) but also pro-sexual effects of drugs with a high predictive validity.

The brain mechanisms involved in the slow onset of sexual inhibiting effects of SSRIs and SNRIs in man and animals are far from being understood although increased serotonergic neurotransmission due to chronic blockade of the serotonin transporter plays an important role. In rats that lack the serotonin transporter from conception, serotonergic neurotransmission is lifelong enhanced which leads to various behavioral and physiological adaptations. Male serotonin transporter homozygous knockout (SERT $-/-)$ rats, trained similarly as wild type rats $($ SERT $+/+)$, display a basal lower level of sexual behavior in our routine sexual behavior test, confirming that long-term enhanced 5-HT neurotransmission is associated with a basal lower level of male sexual behavior. The SERT-/- rat model can be used to study effects of complex antidepressant drugs with various mechanisms that still have SSRI as main antidepressant principle (e.g., vilazodone or vortioxetine). This model also enables to study adaptations in neuroplasticity mechanisms induced by longterm-enhanced serotonin levels in the brain, including the functional status of various serotonergic receptors or other neurotransmitter systems and their receptors. Preliminary studies have shown the value of the SERT $-/-$ model in the role of $5-\mathrm{HT}_{1 \mathrm{~A}}$-receptors in male sexual behavior, as well as in the search for mechanisms involved in the acute (on-demand) sexual inhibiting effects of tramadol.

\section{Compliance with Ethical Standards}

Conflict of Interest The authors declare that they have no conflicts of interest.

Human and Animal Rights and Informed Consent Studies/experiments with human or animal subjects performed by the authors have been previously published and complied with all applicable ethical standards (including the Helsinki declaration and its amendments, institutional/ national research committee standards, and international/national/institutional guidelines.

Open Access This article is distributed under the terms of the Creative Commons Attribution 4.0 International License (http:// creativecommons.org/licenses/by/4.0/), which permits unrestricted use, distribution, and reproduction in any medium, provided you give appropriate credit to the original author(s) and the source, provide a link to the Creative Commons license, and indicate if changes were made.

\section{References}

Papers of particular interest, published recently, have been highlighted as:

- Of importance

-• Of major importance

1. Montejo-Gonzalez AL, Llorca G, Izquierdo JA, Ledesma A, Bousono M, Calcedo A, et al. SSRI-induced sexual dysfunction: fluoxetine, paroxetine, sertraline, and fluvoxamine in a prospective, multicenter, and descriptive clinical study of 344 patients. J Sex Marital Ther. 1997;23(3):176-94.

2. Montejo AL, Montejo L, Navarro-Cremades F. Sexual side-effects of antidepressant and antipsychotic drugs. Curr Opin Psychiatry. 2015;28(6):418-23.

3. Segraves RT. Sexual dysfunction associated with antidepressant therapy. Urol Clin North Am. 2007;34(4):575-9 vii.

4. Segraves RT, Balon R. Antidepressant-induced sexual dysfunction in men. Pharmacol Biochem Behav. 2014;121:132-7.

5.• Chokka PR, Hankey JR. Assessment and management of sexual dysfunction in the context of depression. Ther Adv Psychopharmacol. 2018;8(1):13-23 Sexual dysfunction (SD) is difficult to diagnose, and because depression is often associated with SD, treatment with antidepressants like the SSRIs complicates the diagnosis considerably, often leading to non-compliance. The review extensively describes the procedures 
physicians have to follow to separate the effects of the disorder from the those of the medication.

6. Montejo A, Majadas S, Rizvi SJ, Kennedy SH. The effects of agomelatine on sexual function in depressed patients and healthy volunteers. Hum Psychopharmacol. 2011;26(8):537-42.

7. Beaumont G. Sexual side-effects of clomipramine (Anafranil). J Int Med Res. 1977;5(1 Suppl):37-44.

8. Harrison WM, Rabkin JG, Ehrhardt AA, Stewart JW, McGrath PJ, Ross D, et al. Effects of antidepressant medication on sexual function: a controlled study. J Clin Psychopharmacol. 1986;6(3):144-9.

9. Monteiro WO, Noshirvani HF, Marks IM, Lelliott PT. Anorgasmia from clomipramine in obsessive-compulsive disorder. A controlled trial. Br J Psychiatry. 1987;151:107-12.

10. Chan JS, Olivier B, de Jong TR, Snoeren EM, Kooijman E, van Hasselt FN, et al. Translational research into sexual disorders: pharmacology and genomics. Eur J Pharmacol. 2008;585(2-3):426-35.

11. Olivier B, Chan JS, Pattij T, de Jong TR, Oosting RS, Veening JG, et al. Psychopharmacology of male rat sexual behavior: modeling human sexual dysfunctions? Int J Impot Res. 2006;18(Suppl 1): S14-23.

12. Waldinger MD, Olivier B. Selective serotonin reuptake inhibitorinduced sexual dysfunction: clinical and research considerations. Int Clin Psychopharmacol. 1998;13(Suppl 6):S27-33.

13. Mos J, Mollet I, Tolboom JT, Waldinger MD, Olivier B. A comparison of the effects of different serotonin reuptake blockers on sexual behaviour of the male rat. Eur Neuropsychopharmacol. 1999;9(1-2):123-35.

14. Pattij T, de Jong TR, Uitterdijk A, Waldinger MD, Veening JG, Cools AR, et al. Individual differences in male rat ejaculatory behaviour: searching for models to study ejaculation disorders. Eur J Neurosci. 2005;22(3):724-34

15. Pattij T, Olivier B, Waldinger MD. Animal models of ejaculatory behavior. Curr Pharm Des. 2005;11(31):4069-77.

16. Bijlsma EY, Chan JS, Olivier B, Veening JG, Millan MJ, Waldinger MD, et al. Sexual side effects of serotonergic antidepressants: mediated by inhibition of serotonin on central dopamine release? Pharmacol Biochem Behav. 2014;121:88-101.

17. Chan JS, Waldinger MD, Olivier B, Oosting RS. Drug-induced sexual dysfunction in rats. Current Protocols in Neuroscience 2010;53(1).

18. Janssen PK, Schaik R, Olivier B, Waldinger MD. The 5- $\mathrm{HT}_{2 \mathrm{C}}$ receptor gene Cys23Ser polymorphism influences the intravaginal ejaculation latency time in Dutch Caucasian men with lifelong premature ejaculation. Asian J Androl. 2014;16(4):607-10.

19. Janssen PK, van Schaik R, Zwinderman AH, Olivier B, Waldinger MD. The 5-HT(1)A receptor C(1019)G polymorphism influences the intravaginal ejaculation latency time in Dutch Caucasian men with lifelong premature ejaculation. Pharmacol Biochem Behav. $2014 ; 121: 184-8$

20. Waldinger MD, Rietschel M, Nothen MM, Hengeveld MW, Olivier B. Familial occurrence of primary premature ejaculation. Psychiatr Genet. 1998;8(1):37-40.

21. Mos J, Olivier B, Bloetjes K, Poth M. Drug-induced facilitation of sexual behaviour in the male rat: behavioural and pharmacological aspects. In: Slob AK, Baum MJ, editors. Psychoneuroendocrinology of Growth and Development. Rotterdam: Medicom; 1990. p. 221-32.

22. Olivier B, Mos J. Animal Psychobiology. In: Archer T, Hansen S, editors. Behavioural biology: neuroendocrine axis. Hilsdale: Lawrence Erlbaum; 1991. p. 207-27.

23. Olivier B, Mos J. Effects of psychotropic drugs on sexual behaviour in male rats. In: Olivier B, Mos J, editors. Depression, anxiety and aggression: preclinical and clinical interfaces. Houten: Medidact; 1988. p. $121-34$.
24. Balon R. Modifications of the serotonin system by antidepressant treatments: implications for the therapeutic response in major depression. Am J Psychiatry. 2006;163:1504-9.

25. Feiger A, Kiev A, Shrivastava RK, Wisselink PG, Wilcox CS. Nefazodone versus sertraline in outpatients with major depression: focus on efficacy, tolerability, and effects on sexual function and satisfaction. J Clin Psychiatry. 1996;57(Suppl 2):53-62.

26. Ramaker MJ, Dulawa SC. Identifying fast-onset antidepressants using rodent models. Mol Psychiatry. 2017;22(5):656-65.

27. Song $\mathrm{C}$, Leonard BE. The olfactory bulbectomised rat as a model of depression. Neurosci Biobehav Rev. 2005;29(4-5):627-47.

28. Vinkers CH, Breuer ME, Westphal KG, Korte SM, Oosting RS, Olivier B, et al. Olfactory bulbectomy induces rapid and stable changes in basal and stress-induced locomotor activity, heart rate and body temperature responses in the home cage. Neuroscience. 2009;159(1):39-46.

29. Breuer ME, Groenink L, Oosting RS, Westenberg HG, Olivier B. Long-term behavioral changes after cessation of chronic antidepressant treatment in olfactory bulbectomized rats. Biol Psychiatry. 2007;61(8):990-5.

30. Breuer ME, Chan JS, Oosting RS, Groenink L, Korte SM, Campbell $\mathrm{U}$, et al. The triple monoaminergic reuptake inhibitor DOV 216,303 has antidepressant effects in the rat olfactory bulbectomy model and lacks sexual side effects. Eur Neuropsychopharmacol. 2008;18(12):908-16.

31. Cantor JM, Binik YM, Pfaus JG. Chronic fluoxetine inhibits sexual behavior in the male rat: reversal with oxytocin. Psychopharmacology. 1999;144(4):355-62.

32. Vega Matuszcyk J, Larsson K, Eriksson E. The selective serotonin reuptake inhibitor fluoxetine reduces sexual motivation in male rats. Pharmacol Biochem Behav. 1998;60(2):527-32.

33. Zhang LM, Wang XY, Zhao N, Wang YL, Hu XX, Ran YH, et al. Neurochemical and behavioural effects of hypidone hydrochloride (YL-0919): a novel combined selective 5-HT reuptake inhibitor and partial 5-HT1A agonist. Br J Pharmacol. 2017;174(9):769-80.

34. Waldinger MD, Zwinderman AH, Olivier B. On-demand treatment of premature ejaculation with clomipramine and paroxetine: a randomized, double-blind fixed-dose study with stopwatch assessment. Eur Urol. 2004;46(4):510-5.

35. Caldarone BJ, Paterson NE, Zhou J, Brunner D, Kozikowski AP, Westphal KG, et al. The novel triple reuptake inhibitor JZAD-IV-22 exhibits an antidepressant pharmacological profile without locomotor stimulant or sensitization properties. J Pharmacol Exp Ther. 2010;335(3):762-70.

36. Coleman CC, King BR, Bolden-Watson C, Book MJ, Segraves RT, Richard N, et al. A placebo-controlled comparison of the effects on sexual functioning of bupropion sustained release and fluoxetine. Clin Ther. 2001;23(7):1040-58.

37. Kennedy SH, Fulton KA, Bagby RM, Greene AL, Cohen NL, RafiTari S. Sexual function during bupropion or paroxetine treatment of major depressive disorder. Can J Psychiatr. 2006;51(4):234-42.

38. Landén M, Hogberg P, Thase ME. Incidence of sexual side effects in refractory depression during treatment with citalopram or paroxetine. J Clin Psychiatry. 2005;66(1):100-6.

39. Oosting RS, Chan JS, Olivier B, Banerjee P, Choi YK, Tarazi F. Differential effects of vilazodone versus citalopram and paroxetine on sexual behaviors and serotonin transporter and receptors in male rats. Psychopharmacology. 2016;233(6):1025-34.

40.•• Oosting RS, Chan JSW, Olivier B, Banerjee P. Vilazodone does not inhibit sexual behavior in male rats in contrast to paroxetine: a role for 5-HT1A receptors? Neuropharmacology. 2016;107:271-7 Evidence that 5-HT ${ }_{1 \mathrm{~A}}$-receptor agonistic effects of vilazodone counteract the inhibitory effects of the SSRI mechanism in the same molecule. This principle found in male rat sexual behavior is translatable to the human situation. 
41. Hamidi-Madani A, Motiee R, Mokhtari G, Nasseh H, Esmaeili S, Kazemnezhad E. The efficacy and safety of on-demand tramadol and paroxetine use in treatment of life long premature ejaculation: a randomized double-blind placebo-controlled clinical trial. J Reprod Infertil. 2018;19(1):10-5.

42. de Jong TR, Pattij T, Veening JG, Waldinger MD, Cools AR, Olivier B. Effects of chronic selective serotonin reuptake inhibitors on 8-OH-DPAT-induced facilitation of ejaculation in rats: comparison of fluvoxamine and paroxetine. Psychopharmacology. 2005;179(2):509-15.

43. de Jong TR, Pattij T, Veening JG, Dederen PJ, Waldinger MD, Cools AR, et al. Effects of chronic paroxetine pretreatment on (+/-)-8-hydroxy-2-(di-n-propyl-amino)tetralin induced c-fos expression following sexual behavior. Neuroscience. 2005;134(4): 1351-61.

44. Clayton AH, Croft HA, Horrigan JP, Wightman DS, Krishen A, Richard NE, et al. Bupropion extended release compared with escitalopram: effects on sexual functioning and antidepressant efficacy in 2 randomized, double-blind, placebo-controlled studies. J Clin Psychiatry. 2006;67(5):736-46.

45. Clayton AH, Gommoll C, Chen D, Nunez R, Mathews M. Sexual dysfunction during treatment of major depressive disorder with vilazodone, citalopram, or placebo: results from a phase IV clinical trial. Int Clin Psychopharmacol. 2015;30(4):216-23.

46. de Jong TR, Pattij T, Veening JG, Dederen PJ, Waldinger MD, Cools AR, et al. Citalopram combined with WAY 100635 inhibits ejaculation and ejaculation-related Fos immunoreactivity. Eur J Pharmacol. 2005;509(1):49-59.

47. Croft H, Settle E Jr, Houser T, Batey SR, Donahue RM, Ascher JA. A placebo-controlled comparison of the antidepressant efficacy and effects on sexual functioning of sustained-release bupropion and sertraline. Clin Ther. 1999;21(4):643-58.

48. Segraves RT, Kavoussi R, Hughes AR, Batey SR, Johnston JA, Donahue R, et al. Evaluation of sexual functioning in depressed outpatients: a double-blind comparison of sustained-release bupropion and sertraline treatment. J Clin Psychopharmacol. 2000;20(2):122-8.

49. Thase ME, Clayton AH, Haight BR, Thompson AH, Modell JG, Johnston JA. A double-blind comparison between bupropion XL and venlafaxine XR: sexual functioning, antidepressant efficacy, and tolerability. J Clin Psychopharmacol. 2006;26(5):482-8.

50. Landén M, Eriksson E, Agren H, Fahlen T. Effect of buspirone on sexual dysfunction in depressed patients treated with selective serotonin reuptake inhibitors. J Clin Psychopharmacol. 1999;19(3): 268-71.

51. Skolnick P, Popik P, Janowsky A, Beer B, Lippa AS. Antidepressant-like actions of DOV 21,947: a "triple" reuptake inhibitor. Eur J Pharmacol. 2003;461(2-3):99-104.

52. Skolnick P, Krieter P, Tizzano J, Basile A, Popik P, Czobor P, et al. Preclinical and clinical pharmacology of DOV 216,303, a "triple" reuptake inhibitor. CNS Drug Rev. 2006;12(2):123-34.

53. Tran P, Skolnick P, Czobor P, Huang NY, Bradshaw M, McKinney A, et al. Efficacy and tolerability of the novel triple reuptake inhibitor amitifadine in the treatment of patients with major depressive disorder: a randomized, double-blind, placebo-controlled trial. J Psychiatr Res. 2012;46(1):64-71.

54. Deardorff WJ, Grossberg GT. A review of the clinical efficacy, safety and tolerability of the antidepressants vilazodone, levomilnacipran and vortioxetine. Expert Opin Pharmacother. 2014 Dec;15(17):2525-42.

55. Khan A, Cutler AJ, Kajdasz DK, Gallipoli S, Athanasiou M, Robinson DS, et al. A randomized, double-blind, placebo-controlled, 8-week study of vilazodone, a serotonergic agent for the treatment of major depressive disorder. J Clin Psychiatry. 2011;72(4):441-7.
56. Clayton AH, Kennedy SH, Edwards JB, Gallipoli S, Reed CR. The effect of vilazodone on sexual function during the treatment of major depressive disorder. J Sex Med. 2013;10(10):2465-76.

57. Gibb A, Deeks ED. Vortioxetine: first global approval. Drugs. 2014;74(1):135-45.

58. Sanchez C, Asin KE, Artigas F. Vortioxetine, a novel antidepressant with multimodal activity: review of preclinical and clinical data. Pharmacol Ther. 2015;145:43-57.

59.• Li Y, Pehrson AL, Oosting RS, Gulinello M, Olivier B, Sanchez C. A study of time- and sex-dependent effects of vortioxetine on rat sexual behavior: possible roles of direct receptor modulation. Neuropharmacology. 2017;15(121):89-99 Vortioxetine is an SSRI with additional serotonergic mechanisms. The male rat sexual behavior model predicts that vortioxetine is not associated with sexual side effects in humans. Clinical data so far seem to confirm this prediction.

60. Kirby EW, Carson CC, Coward RM. Tramadol for the management of premature ejaculation: a timely systematic review. Int J Impot Res. 2015;27(4):121-7.

61. Olivier JD, Esquivel Franco DC, Oosting R, Waldinger M, Sarnyai Z, Olivier B. Tramadol: Effects on sexual behavior in male rats are mainly caused by its 5-HT reuptake blocking effects. Neuropharmacology. 2017;116:50-8 A dose-response study on the effects of tramadol on male sexual behavior in the rat. The results illustrate the contributions of pharmacology in deciphering the underlying mechanisms of tramadol's inhibition, but also illustrate the complicated role of various neurotransmitter systems in the expression of male sexual behavior.

62. Esquivel-Franco DC, Olivier B, Waldinger MD, Gutierrez-Ospina G, Olivier JDA. Tramadol's inhibitory effects on sexual behavior: pharmacological studies in serotonin transporter knockout rats. Front Pharmacol. 2018;9:676.

63.• Jian Z, Wei X, Ye D, Li H, Wang K. Pharmacotherapy of premature ejaculation: a systematic review and network meta-analysis. Int Urol Nephrol. 2018;50(11):1939-48 A systematic and thorough literature search on pharmacotherapy of premature ejaculation (PE). Using the intravaginal ejaculation time (IELT), many studies were reviewed and enrolled into network meta-analysis. Besides the SSRIs, also, tramadol appeared effective in lengthening the IELT.

64. Waldinger MD. Drug treatment options for premature ejaculation. Expert Opin Pharmacother. 2018;19(10):1077-85 Describes the various drugs available for treatment of lifelong and acquired premature ejaculation (PE). Many products, registered or not, are used for $\mathrm{PE}$ and the author critically reviews available data. SSRIs are the main treatment for PE, although, except for dapoxetine, all are used off-label. Although dapoxetine has some on-demand effects in PE, effects are small and the compound is not favored for long-term use.

65. Andersson KE, Mulhall JP, Wyllie MG. Pharmacokinetic and pharmacodynamic features of dapoxetine, a novel drug for 'on-demand' treatment of premature ejaculation. BJU Int. 2006;97(2):311-5.

66. Giuliano F, Clement P. Pharmacology for the treatment of premature ejaculation. Pharmacol Rev. 2012;64(3):621-44.

67. Waldinger MD, Schweitzer DH, Olivier B. On-demand SSRI treatment of premature ejaculation: pharmacodynamic limitations for relevant ejaculation delay and consequent solutions. J Sex Med. 2005;2(1):121-31.

68. Artigas F. Serotonin receptors involved in antidepressant effects. Pharmacol Ther. 2013;137(1):119-31.

69. Mondaini N, Fusco F, Cai T, Benemei S, Mirone V, Bartoletti R. Dapoxetine treatment in patients with lifelong premature ejaculation: the reasons of a "Waterloo". Urology. 2013;82(3):620-4.

70. Olivier B, Chan JS, Snoeren EM, Olivier JD, Veening JG, Vinkers $\mathrm{CH}$, et al. Differences in sexual behaviour in male and female rodents: role of serotonin. Curr Top Behav Neurosci. 2011;8:15-36. 
71. Blier P. de MC, Chaput Y. Modifications of the serotonin system by antidepressant treatments: implications for the therapeutic response in major depression. J Clin Psychopharmacol. 1987;7(6 Suppl): 24S-35S.

72. Hull EM, Muschamp JW, Sato S. Dopamine and serotonin: influences on male sexual behavior. Physiol Behav. 2004;83(2):291307.

73. Will RG, Hull EM, Dominguez JM. Influences of dopamine and glutamate in the medial preoptic area on male sexual behavior. Pharmacol Biochem Behav. 2014;121:115-23.

74. Paterson NE, Balci F, Campbell U, Olivier BE, Hanania T. The triple reuptake inhibitor DOV216,303 exhibits limited antidepressant-like properties in the differential reinforcement of low-rate 72-second responding assay, likely due to dopamine reuptake inhibition. J Psychopharmacol. 2011;25(10):1357-64.

75. Olivier B. Serotonin: a never-ending story. Eur J Pharmacol. 2015;753:2-18

76.• Olivier JDA, Esquivel Franco DC, Waldinger MD, Olivier B. Serotonin and sexual behavior. In: Tricklebank M, Daly E, editors. The serotonin system: history, neuropharmacology, and pathology. Elsevier; 2019. Chapter 7; p117-32. Review of the role of serotonin in male and female sexual behavior, mainly focusing on rats and humans.

77. Ahlenius S, Larsson K, Svensson L, Hjorth S, Carlsson A, Lindberg $\mathrm{P}$, et al. Effects of a new type of 5-HT receptor agonist on male rat sexual behavior. Pharmacol Biochem Behav. 1981;15(5):785-92.

78. Snoeren EM, Veening JG, Olivier B, Oosting RS. Serotonin 1A receptors and sexual behavior in female rats: a review. Pharmacol Biochem Behav. 2014;121:43-52.

79. Jastrzebska-Wiesek M, Partyka A, Rychtyk J, Sniecikowska J, Kolaczkowski M. esolowska A, et al. Activity of serotonin 5$\mathrm{HT}_{1 \mathrm{~A}}$-receptor biased agonists in rat: anxiolytic and antidepressant-like properties. ACS Chem Neurosci. 2018;9(5): 1040-50.

80. Millan MJ. Multi-target strategies for the improved treatment of depressive states: conceptual foundations and neuronal substrates, drug discovery and therapeutic application. Pharmacol Ther. 2006;110(2):135-370.

81. Waldinger MD, Zwinderman AH, Olivier B. Antidepressants and ejaculation: a double-blind, randomized, fixed-dose study with mirtazapine and paroxetine. J Clin Psychopharmacol. 2003;23(5): $467-70$.

82. Atmaca M, Korkmaz S, Topuz M, Mermi O. Mirtazapine augmentation for selective serotonin reuptake inhibitor-induced sexual dysfunction: a retropective investigation. Psychiatry Investig. 2011;8(1):55-7.

83. Ozmenler NK, Karlidere T, Bozkurt A, Yetkin S, Doruk A, Sutcigil $\mathrm{L}$, et al. Mirtazapine augmentation in depressed patients with sexual dysfunction due to selective serotonin reuptake inhibitors. Hum Psychopharmacol. 2008;23(4):321-6.

84. Dekeyne A, la Mannoury CC, Gobert A, Brocco M, Lejeune F, Serres F, et al. S32006, a novel 5-HT2C receptor antagonist displaying broad-based antidepressant and anxiolytic properties in rodent models. Psychopharmacology. 2008;199(4):549-68.

85. Millan MJ, Brocco M, Gobert A, Dekeyne A. Anxiolytic properties of agomelatine, an antidepressant with melatoninergic and serotonergic properties: role of 5-HT2C receptor blockade. Psychopharmacology. 2005;177(4):448-58.

86. Popa D, Cerdan J, Reperant C, Guiard BP, Guilloux JP, David DJ, et al. A longitudinal study of 5-HT outflow during chronic fluoxetine treatment using a new technique of chronic microdialysis in a highly emotional mouse strain. Eur J Pharmacol. 2010;628(1-3): 83-90.

87. Quentin E, Belmer A, Maroteaux L. Somato-dendritic regulation of raphe serotonin neurons: a key to antidepressanta. Front Neurosci. 2018:12-982 Important for the idea is how the serotonergic system works under normal conditions. Serotonergic neurons fire tonically, clockwise. Adding SSRIs to the system interferes with this pattern and leads to adaptations of the serotonergic system, including downregulation of $5-\mathrm{HT}_{1 \mathrm{~A}}$ autoreceptors. How does this fit with the effects of serotonergic activity on male sexual behavior?

88.• Alboni S, van Dijk RM, Poggini S, Milior G, Perrotta M, Drenth T, et al. Fluoxetine effects on molecular, cellular and behavioral endophenotypes of depression are driven by the living environment. Mol Psychiatry. 2017;22(4):552-61 Although SSRIs are the most commonly used antidepressants, their efficacy is variable and incomplete. This article focuses on the environmental influences on the effects of SSRIs and suggests that an enriched environment might be benificial when associated with SSRI treatment. This is an interesting hypothesis that should also be investigated in the present rat model and the SERTknockout rat

89. Smits BM, Mudde JB, van de Belt J, Verheul M, Olivier J, Homberg J, et al. Generation of gene knockouts and mutant models in the laboratory rat by ENU-driven target-selected mutagenesis. Pharmacogenet Genomics. 2006;16(3):159-69.

90. Homberg JR, Olivier JD, Smits BM, Mul JD, Mudde J, Verheul M, et al. Characterization of the serotonin transporter knockout rat: a selective change in the functioning of the serotonergic system. Neuroscience. 2007;146(4):1662-76.

91. Kalueff AV, Olivier JD, Nonkes LJ, Homberg JR. Conserved role for the serotonin transporter gene in rat and mouse neurobehavioral endophenotypes. Neurosci Biobehav Rev. 2010;34(3):373-86.

92. Chan JS, Snoeren EM, Cuppen E, Waldinger MD, Olivier B, Oosting RS. The serotonin transporter plays an important role in male sexual behavior: a study in serotonin transporter knockout rats. J Sex Med. 2011;8(1):97-108.

93. Frink MC, Hennies HH, Englberger W, Haurand M, Wilffert B. Influence of tramadol on neurotransmitter systems of the rat brain. Arzneimittelforschung. 1996;46(11):1029-36.

94. Matthiesen T, Wohrmann T, Coogan TP, Uragg H. The experimental toxicology of tramadol: an overview. Toxicol Lett. 1998;95(1): 63-71.

Publisher's Note Springer Nature remains neutral with regard to jurisdictional claims in published maps and institutional affiliations. 